\title{
KUALITAS HIDUP PASIEN PASCA-PERCUTANEOUS CORONARY INTERVENTION (PCI)
}

\author{
${ }^{1}$ Dian Anggraini, ${ }^{2}$ Teo Zumibakti Andani \\ STIKep PPNI Jawa Barat, Bandung, Jawa Barat - Indonesia \\ E-mail: dians_23@yahoo.com
}

\begin{abstract}
Abstrak
Serangan jantung biasanya disebabkan oleh penyumbatan yang mencegah darah mengalir ke jantung atau otak, sehingga dapat terjadi kerusakan atau komplikasi lebih lanjut seperti; miokard infark (kematian sel jantung) hingga gagalnya otot jantung dalam mendapatkan suplai oksigen yang dapat mengakibatkan kematian seseorang. Oleh sebab itu, pasien penyakit jantung memerlukan Percutaneous Coronary Intervention (PCI) untuk mengatasi permasalahnya. Pemasangan PCI pada pasien yang menderita penyakit jantung dapat memengaruhi aktivitas fisik pasien hingga kualitas hidupnya (Quality Of Life). Tujuan dari penelitian ini adalah untuk mengetahui gambaran kualitas hidup pasien pasca PCI. Metode penelitian ini menggunakan deskriptif kuantitatif. Populasi dalam penelitian ini pasien percutaneos coronary intervention (PCI) di Rumah Sakit Dustira Cimahi sebanyak 87 kasus.Teknik pengambilan sampel dengan cara purposive sampling dengan jumlah 38 responden. Tehnik pengumpulan data menggunakan kuesioner dan diolah dengan distribusi frekuensi. Hasil penelitian ini menunjukkan bahwa kualitas hidup pasien pasca PCI berdasarkan empat domain kualitas hidup didapatkan hasil pada domain fisik sebagian besar $(73,7 \%)$ kualitas hidup responden rendah, sebagian besar 78,9\% kualitas hidup responden tinggi pada domain psikologi, sebagian besar $63,2 \%$ kualitas hidup responden tinggi dilihat pada domain sosial, sebagian besar 55,3\% kualitas hidup responden tinggi dilihat pada domain lingkungan. Diharapkan perawat dapat memberikan asuhan keperawatan dan memberikan motivasi kepada pasien agar rajin melakukan kontrol, melaksanakan diet serta berhenti merokok.
\end{abstract}

Kata Kunci : Percutaneous Coronary Intervention (PCI), Kualitas Hidup

\begin{abstract}
Heart attacks are usually an acute event, mostly caused by blockages that prevent blood from flowing into the heart or brain. Therefore patients with coronary heart disease require Percutaneous Coronary Intervention (PCI) to overcome this problem. The installation of Percutaneous Coronary Intervention PCI in patients whose suffering from heart disease, can affect their Quality Of Life. The purpose of this research is to described the quality of life in patient after Percutaneous Coronary Intervention (PCI). This research was using Descriptive Quantitative with Cross Sectional approach. The sample in this study was acquired by using Accidental Sampling with 38 respondents. The results of this study indicate that the quality of life of patients post Percutaneous Coronary Intervention (PCI) while based on 4 domains of quality of life obtained result most of 73,7\% quality of life of respondent low in physical domain, most of 78,9\% quality of life of respondent high in psychology domain, most of 63,2\% quality of life of respondent have high quality based on social domain, Most of the $55.3 \%$ of respondents' have high quality of life based on the environment domain. Research is the describe the quality of life in patient with post Percutaneous Coronary Intervention (PCI) based on psychological domain, social domain and environment domain have high quality of life while in low physical domain this is due to age factor.
\end{abstract}

Keywords : Percutaneous Coronary Intervention (PCI) and Quality of Life

\section{PENDAHULUAN}

Serangan jantung biasanya merupakan kejadian akut dan sebagian besar disebabkan oleh penyumbatan yang mencegah darah mengalir ke jantung atau otak. Penyebab utamanya adalah timbunan lemak pada dinding pembuluh darah yang menyuplai hati atau otak, yang dapat menyebabkan kerusakan atau komplikasi lebih lanjut seperti; miokard infark (kematian sel jantung) hingga gagalnya otot jantung dalam mendapatkan suplai oksigen yang dapat mengakibatkan kematian seseorang (Corwin, 2008).

Upaya pencegahan komplikasi lebih lanjut pada jantung dapat berupa komplikasi 
vaskuler, hematoma, sindrom coronary acute (STEMI) yang bisa memperparah kondisi kesehatan yang sebenarnya dapat dicegah, maka dari itu diperlukan salah satu metode agar seseorang dapat bertahan dari serangan jantung, yaitu cara penanganan medis, salah satu di antaranya, yaitu dengan metode Percutaneous Coronary Intervention (PCI).

\section{PCI (Percutaneous Coronary Intervention)} merupakan suatu teknik untuk menghilangkan dan melebarkan pembuluh darah koroner yang menyempit. Tindakan ini dapat menghilangkan penyumbatan dengan segera, sehingga aliran darah dapat menjadi normal kembali, sehingga kerusakan otot jantung dapat dihindari (Majid, 2007), namun pemasangan PCI pada pasien yang menderita penyakit jantung dapat mempengaruhi aktivitas fisik pasien hingga kualitas hidupnya (Quality of Life) (Burhani, 2013).

Menurut World Health Organization (WHO) melalui WHOQOL (World Health Organization Quality of Life) kualitas hidup merupakan suatu persepsi individu tentang keberadaannya dalam hidup yang terkait dengan budaya dan sistem nilai di lingkungan dia berada dalam hubungannya dengan tujuan, harapan, standar, dan hal-hal menarik lainnya (Lucas, 2012). Kualitas hidup dipengaruhi oleh persepsi individu mengenai keadaan mereka dalam kehidupan dalam konteks budaya dan sistem nilai tempat mereka hidup.

Kualitas hidup terdiri dari empat domain, yaitu domain kesehatan fisik yang meliputi nyeri dan ketidaknyamanan, tenaga dan lelah, tidur dan istirahat, pergerakan, aktivitas sehari-hari, ketergantungan, dan kapasitas pekerjaan. Domain psikologis yang meliputi perasaan positif, berfikir, harga diri, penampilan, perasaan negatif, dan spiritual. Domain hubungan sosial yang meliputi hubungan perorangan, dukungan sosial, dan aktivitas sosial. Domain lingkungan yang meliputi keamanan fisik, lingkungan rumah, sumber penghasilan, kesehatan, keterampilan, rekreasi, lingkungan fisik, dan transportasi (Makkau, 2014). Kualitas hidup pasien yang optimal berdasarkan empat domain di atas menjadi isu penting yang harus diperhatikan dalam memberikan pelayanan keperawatan yang komprehensif (Ibrahim, 2009).

Hasil penelitian yang dilakukan oleh Weintraub, et all (2008) pada tahun 1999 hingga tahun 2004, mengenai Effect of PCI on Quality of Life in Patients with Stable Coronary menyimpulkan bahwa dari 35,539 pasien dengan $\mathrm{CAD}$, mengalami peningkatan secara signifikan setelah dilakukan pemasangan PCI terjadi peningkatan baik secara fisik, frekuensi terjadinya angina dan kualitas hidup pasien (Weintraub, et all, 2008).

Hasil wawancara yang dilakukan di Rumah Sakit Dustira Cimahi pada lima orang pasien yang mempunyai penyakit jantung dan sudah menjalani Percutaneous Coronary Intervention (PCI). Pada saat sebelum tindakan Percutaneous Coronary Intervention (PCI) pasien mengatakan bahwa mereka mengalami berbagai macam gangguan baik fisik maupun psikologis seperti terganggu dalam malakukan aktivitas sehari-hari, sering lelah dan sering merasa cemas. Setelah dilakukan tindakan Percutaneous Coronary Intervention (PCI), merasakan adanya perubahan pada dirinya, mereka mengatakan dengan kondisi yang sekarang merasa lebih baik tetapi masih ada sedikit kecemasan karena kurang mengetahui kemungkinan yang akan terjadi setelah dilakukan tindakan Percutaneous Coronary Intervention (PCI).

\section{METODE PENELITIAN}

Penelitian ini menggunakan penelitian deskriptif yang bertujuan untuk mengetahui 
gambaran kualitas hidup terhadap pasien percutaneos coronary intervention (PCI). Pendekatan yang digunakan pada penelitian ini adalah pendekatan cross sectional study dikarenakan variabel pada objek penelitian ini diukur secara simultan dalam waktu yang bersamaan (Notoadmojo, 2010).

\section{Populasi \& Sampel}

Populasi dalam penelitian ini, yaitu pasien percutaneos coronary intervention (PCI) di Rumah Sakit Dustira Cimahi sebanyak 87 kasus.

Sampel dalam penelitian ini sebanyak 38 orang dengan teknik pengambilan sampel Purposif Sampling. Pengumpulan data dipilih sesuai kriteria inklusi dan eksklusi, dalam hal iniresponden yang diambil, yaitu Pasien yang post pemasangan Percutaneous Coronary Intervention $(\mathrm{PCI})>3$ bulan.

\section{Pengumpulan Data}

Metode pengumpulan data pada penelitian ini menggunakan kuesioner. Peneliti berkunjung ke setiap rumah dan memberikan kuesioner dengan mewawancarai responden dan bersedia mengisi informed consent untuk dijadikan subjek penelitian

\section{HASIL PENELITIAN}

\section{a. Karakteristik Responden}

Bagian ini mendeskripsikan karateristik responden gambaran kualitas hidup pasien Pasca Percutaneous Coronary Intervention (PCI) di Rumah Sakit Dustira. Karakteristik responden menurut jenis kelamin, usia, dan pekerjaan dapat dilihat pada tabel berikut:
Tabel 1.

Distribusi Karakteristik Responden

\begin{tabular}{lcc}
\hline Karakteristik & Frekuensi & Persentase \\
\hline Jenis Kelamin & & \\
$\quad$ Laki-laki & 23 & $60,5 \%$ \\
$\quad$ Perempuan & 15 & $39,5 \%$ \\
Usia & & \\
$\quad$ Pralansia & 26 & $68,4 \%$ \\
$\quad(45-59$ & & \\
$\quad$ tahun) & & \\
$\quad$ Lansia (60- & 12 & $31,6 \%$ \\
$\quad 74$ tahun) & & \\
Pekerjaan & & \\
$\quad$ Karyawan & & \\
$\quad$ PNS & 23 & $60,5 \%$ \\
$\quad$ Ibu rumah & 6 & $15,8 \%$ \\
tangga & 9 & $23,7 \%$ \\
\hline$\quad$ Total & 38 & $100 \%$ \\
\hline
\end{tabular}

Tabel 1. di atas menunjukkan bahwa lebih dari setengahnya $(60,5 \%)$ jenis kelamin responden ialah laki-laki dengan rentan usia 45-59 tahun serta memiliki pekerjaan sebesar $60,5 \%$ sebagai karyawan.

\section{b. Domain Fisik}

Tabel 1.2

Distribusi Responden menurut Domain Fisik

\begin{tabular}{lcc}
\hline \multicolumn{1}{c}{ Kategori } & Frekuensi & Persentase \\
\hline Tinggi & 10 & $26,3 \%$ \\
Rendah & 28 & $73,7 \%$ \\
\hline Total & 38 & $100 \%$ \\
\hline
\end{tabular}

Berdasarkan Tabel 2 di atas menunjukkan bahwa lebih dari setengahnya memiliki kualitas hidup yang rendah pada domain fisik sebesar $73,7 \%$. 


\section{c. Domain Psikologis}

Tabel 3.

Distribusi Responden menurut Domain Psikologis

\begin{tabular}{lcc}
\multicolumn{1}{c}{ Kategori } & Frekuensi & Persentase \\
\hline Tinggi & 30 & $78,9 \%$ \\
Rendah & 8 & $21,1 \%$ \\
\hline Total & 38 & $100 \%$ \\
\hline
\end{tabular}

Berdasarkan Tabel 3 di atas menunjukkan bahwa lebih dari setengahnya memiliki kualitas hidup yang tinggi pada domain psikologis sebesar 78,9\%.

\section{d. Domain Sosial}

Tabel 4.

Distribusi Responden menurut Domain Psikologis

\begin{tabular}{ccc}
\hline Kategori & Frekuensi & Persentase \\
\hline Tinggi & 24 & $63,2 \%$ \\
Rendah & 14 & $36,8 \%$ \\
\hline Total & 38 & $100 \%$
\end{tabular}

Berdasarkan Tabel 4 di atas menunjukkan bahwa lebih dari setengahnya memiliki kualitas hidup yang tinggi pada domain sosial sebesar $63,2 \%$.

\section{e. Domain Lingkungan}

Tabel 5.

Distribusi Responden menurut Domain Lingkungan

\begin{tabular}{ccc}
\hline Kategori & Frekuensi & Persentase \\
\hline Tinggi & 21 & $55,3 \%$ \\
Rendah & 17 & $44,7 \%$ \\
\hline Total & 38 & $100 \%$ \\
\hline
\end{tabular}

Berdasarkan Tabel 5 di atas menunjukkan bahwa lebih dari setengahnya memiliki kualitas hidup yang tinggi pada domain fisik sebesar $55,3 \%$.

\section{PEMBAHASAN}

Hasil analisis univariat mengenai kualitas hidup pasien pasca Percutaneous Coronary Intervention (PCI) menunjukkan bahwa sebanyak $73,7 \%$ pasien memiliki kualitas hidup yang rendah pada domain fisik. Hal ini terjadi karena sebagian besar responden memiliki rentang usia pralansia (middle age) 45-59 tahun. Berdasarkan hasil penelitian Rohmah (2012) mengenai "Kualitas Hidup Lanjut Usia" menunjukkan bahwa terdapat pengaruh faktor fisik terhadap kualitas hidup lanjut usia, hal ini dikarenakan pada fase pralansia terjadi perubahan dalam segi fisik kognitif, maupun dalam kehidupannya. Hal ini ditandai dengan munculnya berbagai gejala penyakit yang belum pernah diderita pada usia muda seperti penyakit jantung, khususnya pasien-pasien yang terpasang Percutaneous Coronary Intervention (PCI).

Hasil analisa univariat mengenai kualitas hidup pasien pasca Percutaneous Coronary Intervention (PCI) menunjukkan bahwa sebanyak 78,9\% pasien memiliki kualitas hidup yang tinggi pada domain psikologis. Felce dan Perry (1996) dalam Rifqi (2012) menyebutkan bahwa kesejahteraan psikologis meliputi pengaruh, pemenuhan, stres dan keadaan mental, harga diri, status dan rasa hormat, keyakinan agama, dan seksualitas. Pada fase pralansia dan lansia (elderly), seseorang akan mengalami perubahan dalam segi fisik, kognitif, maupun dalam kehidupan psikososialnya (Rifqi, 2012). Kestabilan kesejahteraan psikologis menjadi salah satu faktor yang ikut berperan dalam meningkatkan kesejahteraan psikologis (Renwick \& Brown, 1996) dalam Rifqi (2012). Kesehatan psikologis mengacu pada afek positif, spiritualitas, berfikir, belajar, memori dan konsentrasi, gambaran diri dan penampilan, harga diri, dan afek negatif (Rapley, 2003).

Kurang dari setengah responden sebanyak $21,1 \%$ pasien memiliki kualitas hidup yang rendah pada domain psikologis. Hal ini disebabkan karena adanya penurunan kemampuan psikologis pada lansia yang disebabkan oleh penurunan fungsi fisiologis. 
Rasa cemas akan penyakit yang dialaminya, merasakan atau sadar akan kematian, perubahan dalam cara hidup seperti kesepian, hidup sendiri, perubahan ekonomi , penyakit kronis dan ketidakmampuan, hilangnya kekuatan dan ketegapan fisik. Hal ini sejalan dengan penelitian yang dilakukan oleh Rizkifani, Perwitasari dan Supadmi pada tahun 2014 didapatkan hasil bahwa 71\% mengalami kualitas hidup rendah pada domain psikologis.

Kesejahteraan psikologis menjadi salah satu faktor yang menentukan kualitas hidup lansia. Faktor psikologis merupakan faktor penting bagi individu untuk melakukan kontrol terhadap semua kejadian yang dialaminya dalam hidup.

Hasil analisis univariat mengenai kualitas hidup pasien pasca Percutaneous Coronary Intervention (PCI) menunjukkan bahwa sebanyak 63,2\% memiliki kualitas hidup yang tinggi pada domain sosial. Kualitas hidup dikenal sebagai indikasi level fungsi sosial pada kesehatan mental (Menlowics \& Stein, 2000; Shahrir, dkk, 2006). Hal ini penting dalam mendukung hubungan sosial (social belonging) dan hubungan komunitas (community belonging) yang merupakan ikatan yang dimiliki oleh seseorang dengan lingkungan sosialnya, di antaranya senang berkumpul dengan teman-teman, mempunyai hubungan sosial, aktif serta tidak mengalami kesulitan dalam hubungan sosial. Aktivitas spiritualitas dan sosial akan memberikan nilai tertinggi bagi lansia untuk menemukan kebermaknaan dan rasa harga dirinya (Syamsuddin, 2008).

Sesuai dengan teori di atas, kesejahteraan sosial menjadi salah satu faktor dalam menentukan kualitas hidup seseorang. Pengukuran well-being melibatkan pemetaan keseluruhan hidup dan mempertimbangkan setiap kejadian dalam hidup atau konteks sosial yang sangat potensial untuk mempengaruhi kualitas hidup individu. Dengan menggunakan istilah kualitas membuat kita mengaitkannya dengan suatu standar kesempurnaan yang berhubungan dengan karakteristik manusia dan nilai-nilai positif seperti kebahagiaan, kesuksesan, kesehatan, dan kepuasan, dalam hal ini hidup mengindikasikan bahwa konsep tersebut menekankan aspek penting pada eksistensi manusia (Syamsuddin, 2008).

Aktivitas-aktivitas sosial akan memberikan nilai tertinggi bagi pralansia atau pun lansia untuk menemukan kebermaknaan dan rasa harga dirinya, dengan banyak berdzikir dan melaksanakan ibadah sehari-hari lansia akan menjadi lebih tenang dalam hidupnya dan kecemasan akan kematian bisa direduksi. Dengan aktif dalam aktivitas sosial, seperti tergabung dalam paguyuban lansia atau karang werdha akan menjadi ajang bagi mereka untuk saling bertukar pikiran, berbagi pengalaman dan saling memberikan perhatian (Syamsuddin, 2008). Oleh karena itu, keaktifan lansia dalam aktivitas sosial akan berdampak pada peningkatan kualitas hidupnya.

Hasil analisis univariat mengenai kualitas hidup pasien pasca Percutaneous Coronary Intervention (PCI) menunjukkan bahwa sebanyak 55, 3\% memiliki kualitas hidup yang tinggi pada domain lingkungan. Kualitas hidup didefinisikan sebagai persepsi seseorang tentang posisinya dalam hidup dalam kaitannya dengan budaya dan sistem tata nilai, dalam hal ini, ia tinggal dalam hubungannya dengan tujuan, harapan, standar, dan hal-hal menarik lainnya (WHOQOL Group, 1994; Nuran, 2009). Kualitas hidup merupakan kontrak multidimensional yang dipengaruhi oleh faktor personal dan lingkungan sekitar, seperti hubungan dekat (intimate relationships), kehidupan 
berkeluarga, pertemanan, dunia kerja, bertetangga, kota tempat tinggal, permukiman, pendidikan, kesehatan, standar hidup, dan keadaan di suatu negara (Schalock dan Parmenter, 2000; Rapley, 2003). Renwick \& Brown (2000) mengemukakan bahwa individu tinggal di dalam suatu lingkup lingkungan yang disebut sebagai tempat tinggal, sehingga kualitas hidup berkaitan dengan di mana lingkungan tempat individu tersebut tinggal.

Sejalan dengan hasil penelitian yang dilakukan oleh Rohmah dkk, (2012) yang menjelaskan bahwa pada faktor lingkungan, mayoritas lanjut usia berada pada kondisi yang cukup memadai dengan jumlah 9 (47\%) lansia. Hal ini didukung oleh pendapat Goode (1994; Nuran, 2009) bahwa kualitas hidup seseorang merefleksikan kekayaan kultural dari seseorang dan mereka yang berada di sekitarnya.

Berdasarkan teori di atas, tempat tinggal harus dapat menciptakan suasana yang tentram, damai, dan menyenangkan bagi para penghuninya sehingga penghuni dapat merasa betah serta merasa terus ingin tinggal di tempat tersebut. Dengan demikian, pralansia dan lanjut usia yang terpasang PCI akan terdukung oleh lingkungan untuk mencapai kualitas hidup yang tinggi. Kualitas hidup individu berkaitan secara intrinsik dengan kualitas hidup orang lain yang berada di lingkungannya.

\section{KESIMPULAN}

1. Sebagian besar $60,5 \%$ responden jenis kelamin responden ialah laki-laki dengan rentan usia 45-59 tahun, berjenis kelamin laki-laki serta memiliki pekerjaan sebagai karyawan.

2. Sebagian besar $73,7 \%$ responden pasca Percutaneous Coronary Intervention (PCI) di Rumah Sakit Dustira Cimahi dengan kualitas hidup rendah dilihat dari domain fisik.

3. Sebanyak 78,9 \% responden pasca Percutaneous Coronary Intervention (PCI) di Rumah Sakit Dustira Cimahi dengan kualitas hidup tinggi dilihat dari domain psikologi.

4. Sebagian besar $63,2 \%$ responden pasca Percutaneous Coronary Intervention (PCI) di Rumah Sakit Dustira Cimahi dengan kualitas hidup tinggi dilihat dari domain sosial.

5. Sebagian besar 55,3 \% responden pasca Percutaneous Coronary Intervention (PCI) di Rumah Sakit Dustira Cimahi dengan kualitas hidup tinggi dilihat dari domain lingkungan.

\section{REFERENSI}

American Heart Association, 2001.ACC/AHA Guidelines For Percutaneous Coronary Intervention (Revision Of The 1993 PTCA Guidelines).2239v-2239xiii.

Arikunto, Suharsimi. (2010). Prosedur Penelitian Suatu Pendekatan Praktik, Cetakan 15, Jakarta: Rineka Cipta

Baim, D. S.,2008. Percutaneous Coronary Intervention In: Fauci, A.S. Et All, Ed. 17thedition Harrison's Principles Of Internal Medicine.New York: McgrawHill, 1459-1465.

Burhani. (2013). Pemetaan Kebutuhan Stent Dan Memprediksikan Jumlah Permintaan Stent Di Masa Mendatang. Jurnal Universitas Gajah Mada, Yogyakarta

Butman, Samuel M.2005. Complications Of Percutaneous

Coronary

Interventions.USA: Springer

Science, 2-4

Cohen, M.D.Et Al (2011). Quality Of Life After Pci With Drug-Eluting Stents For Coronary-Artery Bypass Surgery. The New England Journal Of Medicine. 
Corwin, E.J. (2008). Handbook Of Pathophysiology, Third Edition,The Ohio State University. Columbus. Hal 303.

Depkes RI. 2013. Riset Kesehatan Dasar. Jakarta: Badan Penelitian Dan Pengembangan Kesehatan Kementrian Kesehatan RI.

Ellis, Stephen Geoffrey And David R. Holmes 2006. Strategic Approaches In Coronary Intervention. 3th Edition.USA:Lippincott Williams \& Wilkins 410-42

Eileen. 2007. A Nurse's Guide To Caring For Cardiac Intervention Patients. USA: John Wiley And Sons. 1-7

Firman, D. (2012). Intervensi Koroner Perkutan Primer, Jurnal Kardiologi Indonesia, Jakarta

Griffin, Brian P .2008. Manual of Cardiovascular Medicine. 3th Edition.USA Lippincott Williams \& Wilkins. 814-820

Grossman, William And Donald S. Baim.2006. Grossman's Cardiac Catheterization, Angiography, And Intervention,Edisi 7.Lippincott Williams \& Wilkins 1-9

Hasan, H., 2007. Intervensi Koroner Perkutan Pada Penyakit Jantung Koroner Dan Permasalahannya. Pidato Pengukuhan Jabatan Guru Besar Tetap Bidang Kardiologi Dan Kedokteran Vaskular FK USU

Hidayat, A. Alimul Aziz. (2007). Metode Penelitian Keperawatan Dan Teknik Analisa Data. Jakarta : Salemba Medika.

Hidayat, A. Alimul Aziz. (2009). Metode Penelitian Keperawatan Dan Teknik Analisa Data. Jakarta : Salemba Medika.

Ibrahim, Kusman. (2009). Kualitas Hidup Pada Pasien Gagal Ginjal Kronik Yang Menjalani Hemodialisa. http://www.mkbonline.org/index.php?o ption=

Com_Content\&View=Article $\& I d=130$ :

Kualitas-Hidup Pasien Gagal Ginjal Kronis Yang Menjalani Hemodialisis
$\&$

Catid=1:

Kumpulanartikel\&Itemid=55. Jeremias, Allen. David L. Brown.2009.Cardiac Intensive Care.Ed 2.Elsevier Health Sciences 255-257

Lucas, R. (2012). The WHO Quality Of Life(Whoqol)Questionnaire: Spanish Development And Validation Studies. Quality Life Resp, 21, 161-165. Doi.Org/10.1017/ S1041610212001809.

Majid, A., 2007, Penyakit Jantung Koroner: Patofisiologi, Pencegahan, Dan PengobatanTerkini(Online).(Http://Res pository.Usu.Ac.Id/Bitstream/12345678 9/705/1/08E00124.Pdf.Diakses25 Mei 2013).

Makkau, A.M. (2014). Faktor Yang Mempengaruhi Kualitas Hidup Orang Dengan Hiv Dan Aids (Odha) Di Yayasan Peduli Kelompok Dukungan Sebaya Kota MakassarTahun 2014. Ilmu Kesehatan Masyarakat Universitas Hasanudin,Makasar

Notoatmodjo, Soekijo. (2010). Metodologi Penelitian Kesehatan, Edisi Revisi. Jakarta: Rineka Cipta

Nursalam. (2013) . Metodologi Penelitian Ilmu Keperawatan : Pendekatan Praktis, Edisi 3 .Jakarta : Salemba Medika.

Rachmat, M. (2012). Buku ajar biostatistika: Aplikasi pada penelitian kesehatan. Jakarta:ECG.

Rifqi, S. (2012). Primary Percutaneous Coronary Intervention (Primary PCI), Senjata "Baru" Untuk Melawan Serangan Jantung Akut, Fakultas Kedokteran Universitas Diponegoro/RSUP Dr. Kariadi, Semarang

Sugiyono. (2012). Metode Penelitiankuantitatif Dan Kualitatif Dan $R \& D$. Bandung:Alfabeta

Sutikno E. 2011. Hubungan Antara Fungsi Keluarga Dan Kualitas Hidup Lansia. MedJ Indonesia; 2011:2:73-9.

Virtual Medical Centre, 2013. Cardiovascular System(Heart).

Http://Www.VirtualmedicalCentre.Com /Anatomy/CardiovascularSystemHeart/ 
16\#.Article, Modified: 26/9/2013. Tanggal 27 Januari 2014.

Weintraub, S.W.Et Al., (2008). Effect Of PCI On Quality of Life In Patients With
Stable Coronary Disease. The New England Journal Of Medicine.

Wardhani, W. I, (2014). KAPITA SELEKTA KEDOKTERAN, Jilid 1. Jakarta : Media Aesculapius FK UI. 